Check for updates

Cite this: RSC Adv., 2019, 9, 8137

\title{
Cross-linked poly(ionic liquid) as precursors for nitrogen-doped porous carbons $\dagger$
}

\begin{abstract}
Shifu Cheng, Bihua Chen, Li Qin, Yongya Zhang, Guohua Gao (D) and Mingyuan He*
A soluble and easily dispersive cross-linked poly(ionic liquid), copolymer of 1-vinyl-3-butylimidazolium bromide ([VBIM][Br]) and divinylbenzene (DVB), was used as a precursor for nitrogen doped porous carbons (NPCs) with $\mathrm{SiO}_{2}$ (from tetraethyl orthosilicate) as a template. The NPCs were characterized by infrared (IR) spectroscopy, nitrogen adsorption-desorption, scanning electron microscopy (SEM), transmission electron microscopy (TEM), X-ray diffraction (XRD), Raman spectroscopy, thermo gravimetric analysis (TGA), elemental analysis and $X$-ray photoelectron spectroscopy (XPS). The specific surface area and porosity of NPCs depended on the carbonization temperature, the $\mathrm{SiO}_{2} /[\mathrm{VBIM}][\mathrm{Br}]$ ratio and the precursors. Under the optimized conditions, the NPC prepared from cross-linked poly(ionic liquid), $\mathrm{P}([\mathrm{VBIM}][\mathrm{Br}]-0.1 \mathrm{DVB})$, gave a high specific surface area up to $1324 \mathrm{~m}^{2} \mathrm{~g}^{-1}$. XRD indicated that amorphous and disordered graphitic layers were dominant in NPCs. The nitrogen content was about 45 wt\% in NPCs, and the nitrogen bonding state observed using XPS analysis was mainly pyridinic- and pyrrolic-N. Meanwhile, the cyclic voltammetry, gravimetric charge-discharge curves and electrochemical impedance spectroscopy of the NPCs were also investigated, the specific capacitance was up to $243 \mathrm{~F} \mathrm{~g}^{-1}$ at $0.1 \mathrm{~A} \mathrm{~g}^{-1}$, and the retention ratio was nearly $100 \%$ after charge-discharge cycling 2400 times at $2 \mathrm{~A} \mathrm{~g}^{-1}$ in $6 \mathrm{M} \mathrm{KOH}$ electrolyte.
\end{abstract}

Received 6th December 2018

Accepted 6th March 2019

DOI: 10.1039/c8ra10022e

rsc.li/rsc-advances yields, high nitrogen content and abundant porous structure. The high yields were attributed to the polymerization of nitrile group in the carbonization process. Carbonization of conventional ionic liquids without any cross-linkable functional groups under $\mathrm{N}_{2}$ atmosphere and ambient pressure affords no carbon yield. ${ }^{\mathbf{4 0 , 4 2}}$ In order to solve this problem, Dai et al. successfully utilized the space confinement of the conventional ionic liquids such as 1-butyl-3-methylimidazolium bis(trifluoromethylsulfonyl)-imide ([BMIm] $\left[\mathrm{NTf}_{2}\right]$ ) inside oxide networks (e.g., silica and titania) to prepare NPCs. ${ }^{42}$ Yuan et al. also applied poly[3-cyanomethyl-1-vinylimidazolium bis(trifluoromethanesulfonyl)-imide $\quad\left(\mathrm{P}[\mathrm{CMVIm}]\left[\mathrm{NTf}_{2}\right]\right)$ as a precursor for NPCs in which the polymer backbone acted as the material source, while the bulky counter-anion played a role as a molecular template for the porous. ${ }^{43}$ Subsequently, the same group reported a method for NPCs by carbonization of copolymers of monomeric ionic liquids and divinylbenzene under the $\mathrm{CO}_{2}$ activation. ${ }^{\mathbf{4 4}}$

In this paper, we would report an one-pot method for fabricated NPCs by carbonization of cross-linked poly(ionic liquid) with $\mathrm{SiO}_{2}$ as template. After $\mathrm{SiO}_{2}$ was etched with $\mathrm{HF}$, NPCs with high specific surface area up to $1324 \mathrm{~m}^{2} \mathrm{~g}^{-1}$ and disorder graphitic layers structure were obtained (Fig. 1). These NPCs had high specific electric capacitance amounting to 150$243 \mathrm{~F} \mathrm{~g}^{-1}$ and the retention ratio was nearly $100 \%$ after being charge and discharge 2400 times at a current density of $2 \mathrm{~A} \mathrm{~g}^{-1}$ in $6 \mathrm{M} \mathrm{KOH}$ electrolyte.
Shanghai Key Laboratory of Green Chemistry and Chemical Processes, School of Chemistry and Molecular Engineering, East China Normal University, 3663, North Zhongshan Road, Shanghai, 200062, China. E-mail: ghgao@chem.ecnu.edu.cn; hemingyuan@126.com

$\dagger$ Electronic supplementary information (ESI) available. See DOI: 10.1039/c8ra10022e 


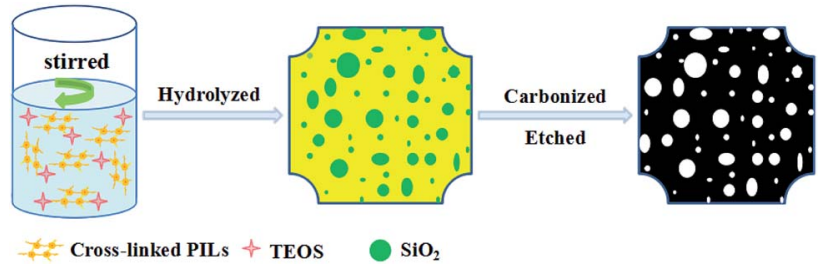

Fig. 1 The process of fabricated NPCs.

\section{Experimental}

\section{Materials}

1-Vinyl-3-butylimidazolium bromide ([VBIM][Br], 99\%) was obtained from Lanzhou Institute of Chemical Physics, Chinese Academy of Sciences. Divinylbenzene (DVB, 55\% mixture of isomers) was purchased from Aladdin. 2,2'-Azobis(2methylpropionitrile) (AIBN, >99\%), $N, N$-dimethylformamide (DMF, >99\%) and tetraethyl orthosilicate (TEOS, 97\%) were purchased from CHINASUN Specialty Products Co., Ltd. Hydrochloric acid (36\%) and hydrofluoric acid (40\%) were purchased from Sinopharm Chemical Reagent Co., Ltd. Solvents and other materials were used as received. Nitrogen $\left(\mathrm{N}_{2}, 99.99 \%\right)$ and air were provided by Air Liquide.

\section{Preparation of cross-linked poly(ionic liquid)}

Cross-linked poly(ionic liquid), $\mathrm{P}([\mathrm{VBIM}][\mathrm{Br}]-0.1 \mathrm{DVB})$, was synthesized by polymerization of ionic liquid monomer and DVB in DMF. In a typical run, [VBIM] [Br] (2.31 g, $10 \mathrm{mmol})$, DVB (0.26 g, $1.1 \mathrm{mmol})$, AIBN (0.164 g, $1 \mathrm{mmol})$ and DMF (15 mL) were loaded into a $100 \mathrm{~mL}$ of reactor. The mixture was stirred at $80{ }^{\circ} \mathrm{C}$ for $24 \mathrm{~h}$ under nitrogen atmosphere. The polymer DMF solution was slowly cooled down to room temperature. The linear PIL, P([VBIM $][\mathrm{Br}])$, was synthesized by polymerization of [VBIM $][\mathrm{Br}]$ without any crosslinker.

\section{Preparation of NPCs}

Typical, TEOS (1.602 g, convert to $\mathrm{SiO}_{2} /[\mathrm{VBIM}][\mathrm{Br}]$ ratio of 0.2) was slowly added to above-mentioned $\mathrm{P}([\mathrm{VBIM}][\mathrm{Br}]-0.1 \mathrm{DVB})$ DMF solutions under stirring. Hydrochloric acid $(0.4 \mathrm{~g})$ and $\mathrm{H}_{2} \mathrm{O}(2.0 \mathrm{~g})$ were added dropwise, and stirred for $30 \mathrm{~min}$. Then a yellow solution was formed. After removed solvent by distillation, faint yellow transparent monolithic gels were obtained. Carbonization was performed by heating the gels to $800{ }^{\circ} \mathrm{C}$ for $1 \mathrm{~h}$ at a heating rate of $5{ }^{\circ} \mathrm{C} \min ^{-1}$ under flowing $\mathrm{N}_{2}$. The carbon-silica composites were cooled down to room temperature, and finely grounded into powders. The powders were dispersed into hydrofluoric acid $(6 \mathrm{~mL})$, and stirred overnight. NPC product $(0.25 \mathrm{~g})$ was obtained by ultracentrifugation, washed four times with deionized water, and dried under vacuum at $120{ }^{\circ} \mathrm{C}$ overnight. Other NPCs with different precursors and carbonization temperatures were prepared by similar methods and denoted as $\mathrm{NPC}_{\mathrm{IL}-x-y}, \mathrm{NPC}_{\mathrm{PIL}-x-y}$ and $\mathrm{NPC}_{\mathrm{P}(\mathrm{IL}-\mathrm{DVB})-x-y}$, where $x$ represented the weight ratio of $\mathrm{SiO}_{2}$ and $[\mathrm{VBIM}][\mathrm{Br}]\left(\mathrm{SiO}_{2}\right.$ from TEOS $)$ and $y$ represented carbonization temperature.

\section{Characterization methods}

${ }^{1} \mathrm{H}-\mathrm{NMR}$ spectra were recorded at $400 \mathrm{MHz}$ on Bruker Ascend 400 spectrometer with tetramethylsilane as the internal standard. IR spectra were measured on a SHIMADZU IR Affinity-1S spectrometer. Thermo gravimetric analysis (TGA) experiments were accomplished on a SDTQ600 apparatus at a heating rate of $10{ }^{\circ} \mathrm{C} \mathrm{min}^{-1}$ under air, and the results were managed by software of Universal Analysis 2000. Scanning electron microscope (SEM) images were obtained on a ZEISS Gemini 300 operated at $20 \mathrm{kV}$ after sputtering gold on the samples. Transmission electron microscope (TEM) images were obtained with a FEI Titan 3 microscope operated at $200 \mathrm{kV}$ after ultrasonic treatment in ethyl alcohol. XRD-measurements were accomplished on a RIGAKU 2550 instrument. Raman-spectra were obtained using a SHIMADZU LabRAM HR Evolution equipped with a $633 \mathrm{~nm}$ laser. Elemental analysis was performed using a Vario EL Elementary. X-ray photoelectron spectroscopy (XPS) measurements were accomplished on a Thermo 250xi device using $\mathrm{Al} \mathrm{K}$ Alpha radiation source. Nitrogen sorption experiments were performed with a Micromeritics ASAP 2020 at $-196{ }^{\circ} \mathrm{C}$. The special surface area was calculated using the BET equation. The pore size distribution was calculated with $\mathrm{BJH}$ an HK methods. The pore volume was calculated at $P / P_{0}$ of 0.999 . The samples were degassed at $250{ }^{\circ} \mathrm{C}$ for $2 \mathrm{~h}$ before measurements.

\section{Electrochemical measurements}

Electrochemical measurements were performed on an electrochemical analyzer system CHI 633A (Chenhua Instrument Company of Shanghai, China). The electrochemical behaviors of the NPCs-based working electrode (80 wt\% NPC, $10 \mathrm{wt} \%$ carbon black and $10 \mathrm{wt} \%$ polytetrafluoroethylene (PTFE)) were analyzed in $6 \mathrm{M} \mathrm{KOH}$ electrolyte in a three-electrode cell. An $\mathrm{Hg}$ / $\mathrm{HgO}$ electrode and a platinum plate were used as the reference electrode and the counter electrode, respectively. The cyclic voltammetry was performed in the potential range of -0.9 to $-0.1 \mathrm{~V}$ with a scan rate from 5 to $100 \mathrm{mV} \mathrm{s}^{-1}$. The specific capacitance $C\left(\mathrm{~F} \mathrm{~g} \mathrm{~g}^{-1}\right)$ was calculated from the gravimetric charge-discharge process according to $C=I \Delta t / \Delta V$, where $I$ was the constant discharge current density $\left(\mathrm{A} \mathrm{g}^{-1}\right)$, and $\Delta t$ was the discharging time, which was measured from -0.9 to $-0.1 \mathrm{~V}$, and $\Delta V$ is the potential change except ohmic drop. The electrochemical impedance spectroscopy tests were carried out in frequency range of $0.01-100 \mathrm{kHz}$.

\section{Results and discussion}

\section{Synthesis of cross-linked poly(ionic liquid) and NPCs}

In order to gained NPCs, the carbon precursor, cross-linked poly(ionic liquid) and template must be mixed homogeneously. The soluble and easy-dispersible cross-linked poly(ionic liquid), $\mathrm{P}([\mathrm{VBIM}][\mathrm{Br}]-0.1 \mathrm{DVB})$, with lower molar ratio of DVB to ionic liquid monomer was synthesized by the polymerization of [VBIM] [Br] and DVB in DMF (Scheme 1).

The ${ }^{1} \mathrm{H}-\mathrm{NMR}$ spectra of $[\mathrm{VBIM}][\mathrm{Br}]$ and $\mathrm{P}([\mathrm{VBIM}][\mathrm{Br}]-$ 0.1DVB) were listed in Fig. 2. The signals around 5.5-7.4 ppm 


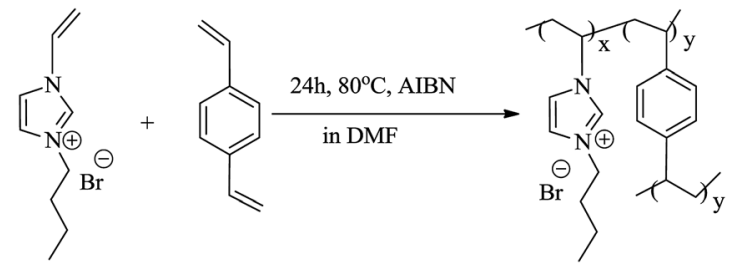

Scheme 1 Synthesis of $\mathrm{P}([\mathrm{VB} \mid \mathrm{M}][\mathrm{Br}]-0.1 \mathrm{DV} B)$.

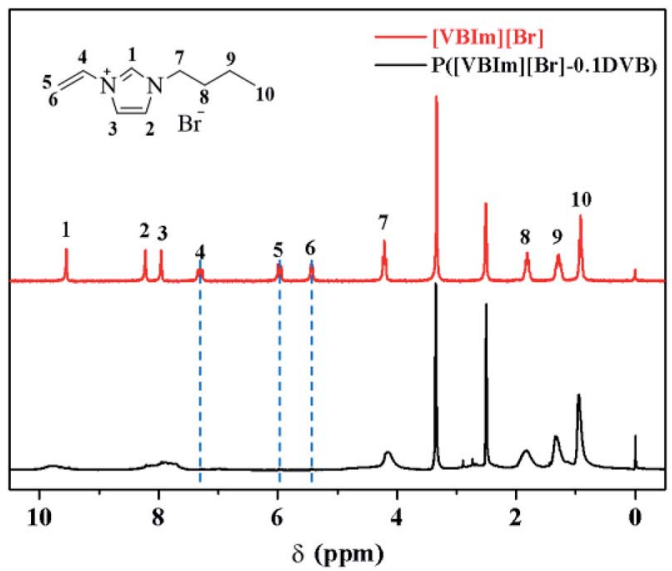

Fig. $2{ }^{1} \mathrm{H}-\mathrm{NMR}$ spectra of [VBIM][Br] and P([VBIM][Br]-0.1DVB).

corresponding to vinyl group were nearly disappeared in $\mathrm{P}([\mathrm{VBIM}][\mathrm{Br}]-0.1 \mathrm{DVB})$, indicating the full polymerization of ionic monomer.

The faint yellow transparent complex gels of $\mathrm{P}([\mathrm{VBIM}][\mathrm{Br}]-$ $0.1 \mathrm{DVB})-\mathrm{SiO}_{2}$ (see Fig. S1a in the ESI $\dagger$ ) were obtained by addition of TEOS dropwise to poly(ionic liquid) DMF solution and subsequent hydrolysis with acid. The complex gels and corresponding carbonization products at different temperature were characterized by IR spectra (see Fig. 3). When the carbonization temperature was below $400{ }^{\circ} \mathrm{C}$, the adsorption peaks of the sample around $1163 \mathrm{~cm}^{-1}$ assigned to $\mathrm{C}-\mathrm{N}$ stretching vibration of imidazolium ring, $1552 \mathrm{~cm}^{-1}$ assigned to imidazolium ring skeleton $^{4,46}$ were observed, indicating the imidazolium in poly(ionic liquid) was stable. However, when the carbonization temperature increased to $500{ }^{\circ} \mathrm{C}$, the intensities of the peaks at $2856-2960 \mathrm{~cm}^{-1}$ assigned to $\mathrm{C}-\mathrm{H}$ stretching vibration on the alkyl groups decreased dramatically and almost disappeared at the carbonization temperature of $600{ }^{\circ} \mathrm{C}$, indicating the degradation of alkyl groups from imidazolium ring. ${ }^{40}$ In the meanwhile, the intensities of the characteristic peaks around 1552 and $1163 \mathrm{~cm}^{-1}$ decreased concomitantly, indicating the reconstruction of imidazolium ring into carbon occurred. When the carbonization temperature were above $700{ }^{\circ} \mathrm{C}$, there were no any peaks assigned to $\mathrm{P}([\mathrm{VBIM}][\mathrm{Br}]-0.1 \mathrm{DVB})$ (see Fig. $3 \mathrm{~b})$. In the meanwhile, the adsorption peaks related to $\mathrm{SiO}_{2}, 3431 \mathrm{~cm}^{-1}$ of $-\mathrm{OH}$ asymmetric stretching vibration, $1074 \mathrm{~cm}^{-1}$ of $\mathrm{Si}-\mathrm{O}-\mathrm{Si}$ asymmetric stretching vibration, $798 \mathrm{~cm}^{-1}$ and $448 \mathrm{~cm}^{-1}$ of SiO symmetry stretching vibration were observed. ${ }^{47}$ All these results indicated that the starting carbonization temperature was $500{ }^{\circ} \mathrm{C}$, and the optimized carbonization temperature was above $700{ }^{\circ} \mathrm{C}$. The IR spectra of eight NPCs from different carbonization temperatures (see Fig. $\mathrm{S} 2$ in $\mathrm{ESI} \dagger$ ) also gave the similar results.

\section{Characterization of NPCs}

After the complex of NPC-SiO ${ }_{2}$ etched by HF (Fig. 1), black metal luster NPCs (see Fig. S1b in the ESI $\dagger$ ) were obtained. The relationship between surface area and the carbonization temperature, the ratios of $\mathrm{SiO}_{2} /[\mathrm{VBIM}][\mathrm{Br}]$ and the precursor types of NPCs were summarized in Table 1. Carbonization temperature was irreplaceable factor to the microstructure of NPCs from imidazolium-based ionic liquid..$^{\mathbf{8 , 4 0 , 4 8}}$ When the carbonization temperature was $500{ }^{\circ} \mathrm{C}$, the surface area $\left(27 \mathrm{~m}^{2} \mathrm{~g}^{-1}\right)$ and the total pore volume $\left(0.04 \mathrm{~cm}^{3} \mathrm{~g}^{-1}\right)$ of $\mathrm{NPC}_{\mathrm{P}(\mathrm{IL}-\mathrm{DVB})-0.2-500}$ were low (Table 1 , entry 1 ), indicating the incomplete carbonization. With the increase of carbonization temperature to $600{ }^{\circ} \mathrm{C}$, the surface area $\left(1121 \mathrm{~m}^{2} \mathrm{~g}^{-1}\right)$ and the total pore volume $\left(0.98 \mathrm{~cm}^{3} \mathrm{~g}^{-1}\right)$ of $\mathrm{NPC}_{\mathrm{P}(\mathrm{IL}-\mathrm{DVB})-0.2-600}$ increased dramatically. The surface area and total pore volume were slight increase with temperature increasing from 700 to $900{ }^{\circ} \mathrm{C}$. The surface area $\left(1324 \mathrm{~m}^{2} \mathrm{~g}^{-1}\right)$ and total pore volume $\left(1.41 \mathrm{~cm}^{3} \mathrm{~g}^{-1}\right)$ of $\mathrm{NPC}_{\mathrm{P}(\mathrm{IL}-\mathrm{DVB})-0.2-900}$ were
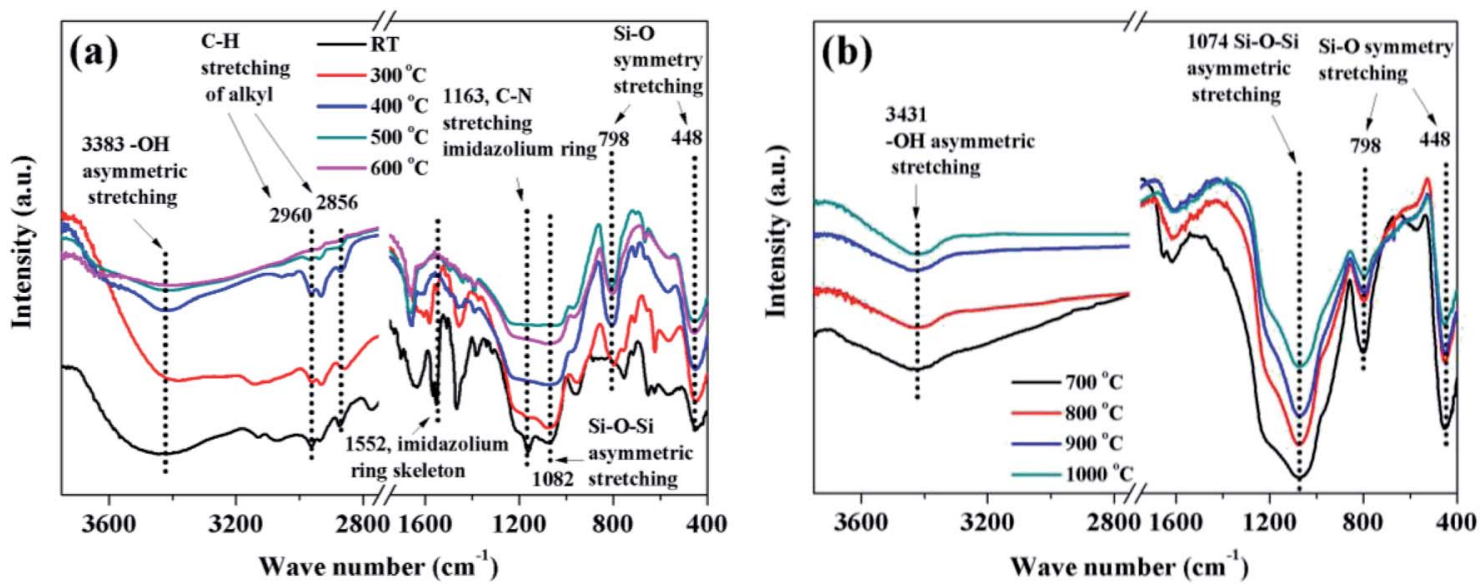

Fig. 3 IR spectra of complex $\mathrm{P}([\mathrm{VBIM}][\mathrm{Br}]-0.1 \mathrm{DVB})-\mathrm{SiO}_{2}$ carbonization at (a) RT-600 ${ }^{\circ} \mathrm{C}$ and (b) $700-1000{ }^{\circ} \mathrm{C}$. 
Table 1 The special surface area and porosity of NPCs

\begin{tabular}{|c|c|c|c|c|c|}
\hline Entry & Samples & $T^{a}\left({ }^{\circ} \mathrm{C}\right)$ & $S_{\text {BET }}\left(\mathrm{m}^{2} \mathrm{~g}^{-1}\right)$ & $V_{\mathrm{t}}\left(\mathrm{cm}^{3} \mathrm{~g}^{-1}\right)$ & Average pore size $(\mathrm{nm})$ \\
\hline 1 & $\mathrm{NPC}_{\mathrm{P}(\mathrm{IL}-\mathrm{DVB})-0.2-500}$ & 500 & 27 & 0.04 & 6.15 \\
\hline 2 & $\mathrm{NPC}_{\mathrm{P}(\mathrm{IL}-\mathrm{DVB})-0.2-600}$ & 600 & 1121 & 0.98 & 3.49 \\
\hline 4 & $\mathrm{NPC}_{\mathrm{P}(\mathrm{IL}-\mathrm{DVB})-0.2-800}$ & 800 & 1297 & 1.33 & 4.11 \\
\hline 5 & $\mathrm{NPC}_{\mathrm{P}(\mathrm{IL}-\mathrm{DVB})-0.2-900}$ & 900 & 1324 & 1.41 & 4.25 \\
\hline 6 & $\mathrm{NPC}_{\mathrm{P}(\mathrm{IL}-\mathrm{DVB})-0.2-1000}$ & 1000 & 1257 & 1.31 & 4.16 \\
\hline 9 & $\mathrm{NPC}_{\mathrm{P}(\mathrm{IL}-\mathrm{DVB})-0.3-800}$ & 800 & 1330 & 1.18 & 3.56 \\
\hline 10 & $\mathrm{NPC}_{\mathrm{P}(\mathrm{IL}-\mathrm{DVB})-0.4-800}$ & 800 & 1285 & 0.93 & 2.89 \\
\hline 11 & $\mathrm{NPC}_{\mathrm{P}(\mathrm{IL}-\mathrm{DVB})-0.5-800}$ & 800 & 1088 & 0.68 & 2.50 \\
\hline 12 & $\mathrm{NPC}_{\mathrm{IL}-0.2-800}$ & 800 & 832 & 0.52 & 2.48 \\
\hline 13 & $\mathrm{NPC}_{\mathrm{PIL}-0.2-800}$ & 800 & 932 & 0.65 & 2.78 \\
\hline
\end{tabular}

maximum in the series of samples. When carbonization temperature increased to $1000{ }^{\circ} \mathrm{C}$, the surface area $\left(1257 \mathrm{~m}^{2} \mathrm{~g}^{-1}\right)$ and total pore volume $\left(1.31 \mathrm{~cm}^{3} \mathrm{~g}^{-1}\right)$ of $\mathrm{NPC}_{\mathrm{P}(\mathrm{IL}-\mathrm{DVB})-0.2-1000}$ decreased slightly on the contrary. The average pore size was about $4.2 \mathrm{~nm}$. These results showed the suitable carbonization temperature was $700-900{ }^{\circ} \mathrm{C} . \mathrm{N}_{2}$ adsorption and desorption isotherms and pore size distribution of NPCs were also listed in Fig. S3a and $\mathrm{c}$ in the ESI. $\dagger$ With carbonization temperature increasing from 500 to $1000{ }^{\circ} \mathrm{C}$, the adsorbing capacity was increasing obviously and the "hysteresis loop" was more obvious at relative pressure from 0.45 to 0.9 due to abundant micropores and mesopores. There were nearly no pores at the carbonization temperature of $500{ }^{\circ} \mathrm{C}$. However, the pores centered at $0.7-0.9 \mathrm{~nm}$ and 2-4 $\mathrm{nm}$ were observed when carbonization temperature was reached to $600{ }^{\circ} \mathrm{C}$, and there were some distribution at 5-20 $\mathrm{nm}$.
Further study was focused on the relationship between surface area and porosity of NPCs and the ratios of $\mathrm{SiO}_{2}$ and [VBIM] [Br] (Table 1, entry 4 and 7-9, Fig. S3b and d $\dagger$ ). With the ratio increasing from 0.05 to 0.3 , the surface area of NPCs increased from 720 to $1330 \mathrm{~m}^{2} \mathrm{~g}^{-1}$. The increase of surface area was due to more space released deriving from $\mathrm{SiO}_{2}$. In contrast, the total pore volume decreased from 1.33 to $1.18 \mathrm{~cm}^{3} \mathrm{~g}^{-1}$, when the ratio increased from 0.2 to 0.3 . With further increase of the ratio to 0.4 and 0.5 , the surface area and average pore size decreased on the contrary (Table 1 , entry 10 and 11). This was possibly attributed to the collapse of large pore produced by excessive $\mathrm{SiO}_{2}$ in the etching process. The surface areas of NPCs from monomer IL ([VBIM] [Br], $832 \mathrm{~m}^{2} \mathrm{~g}^{-1}$ ) and linear PIL $\left(\mathrm{P}([\mathrm{VBIM}][\mathrm{Br}]), 932 \mathrm{~m}^{2} \mathrm{~g}^{-1}\right)$ were relatively low (Table 1, entry 12 and 13), comparing with the NPC from cross-linked poly ionic

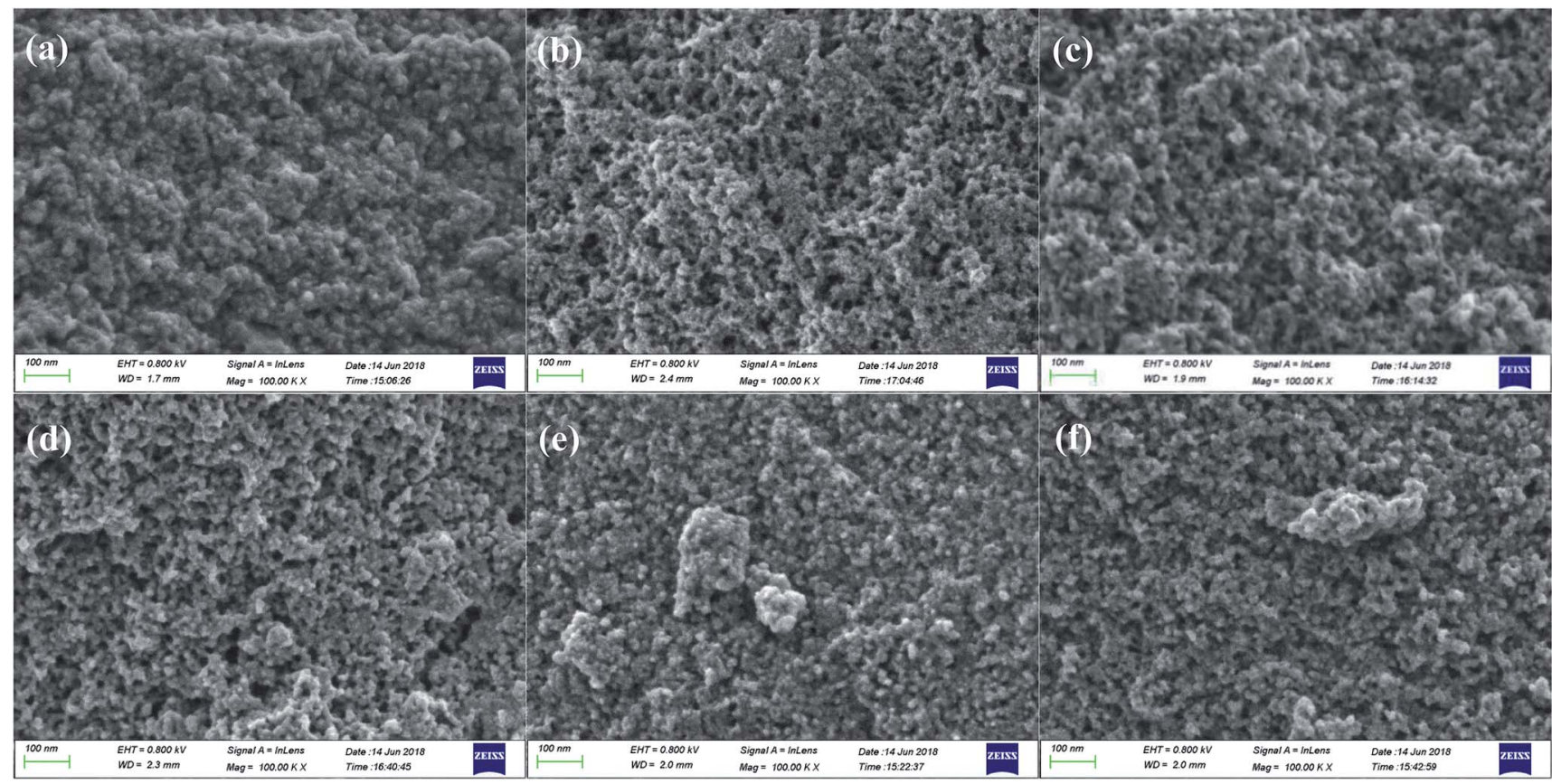

Fig. 4 SEM of NPCs from different carbonization temperature: (a) $500{ }^{\circ} \mathrm{C}$, (b) $600{ }^{\circ} \mathrm{C}$, (c) $700{ }^{\circ} \mathrm{C}$, (d) $800{ }^{\circ} \mathrm{C}$, (e) $900{ }^{\circ} \mathrm{C}$, (f) $1000{ }^{\circ} \mathrm{C}$. 


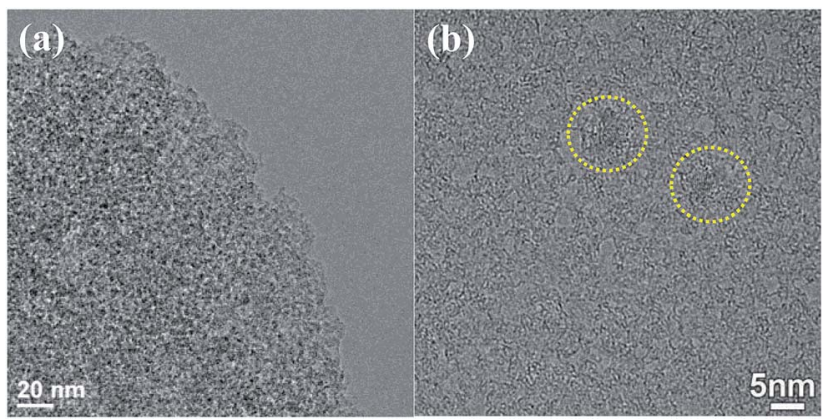

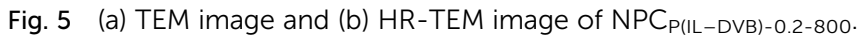

liquid ( $\mathrm{NPC}_{\mathrm{P}(\mathrm{IL}-\mathrm{DVB})-0.2-800)}$ (Table 1, entry 4). The cross-linked copolymer of [VBIM][Br] and DVB may form "framework intermediates" in carbonization, sequentially caused more pores.

The surface microstructure of NPCs from different carbonization temperature $500-1000{ }^{\circ} \mathrm{C}$ was visualized by scanning electron microscope (see Fig. 4). From Fig. 4a-f, the NPCs were composed of "cauli-flower" head which were agglomerated by around $20-50 \mathrm{~nm}$ spherules. When the carbonization temperature was $500{ }^{\circ} \mathrm{C}$, there were scarcely any splits or cavity on $\mathrm{NPC}_{\mathrm{P}(\mathrm{IL}-\mathrm{DVB})-0.2-500}$ surface. With the increase of carbonization temperature to $600{ }^{\circ} \mathrm{C}$, there were abundant splits, mesopores and macropores. Elevating carbonization temperature from 600
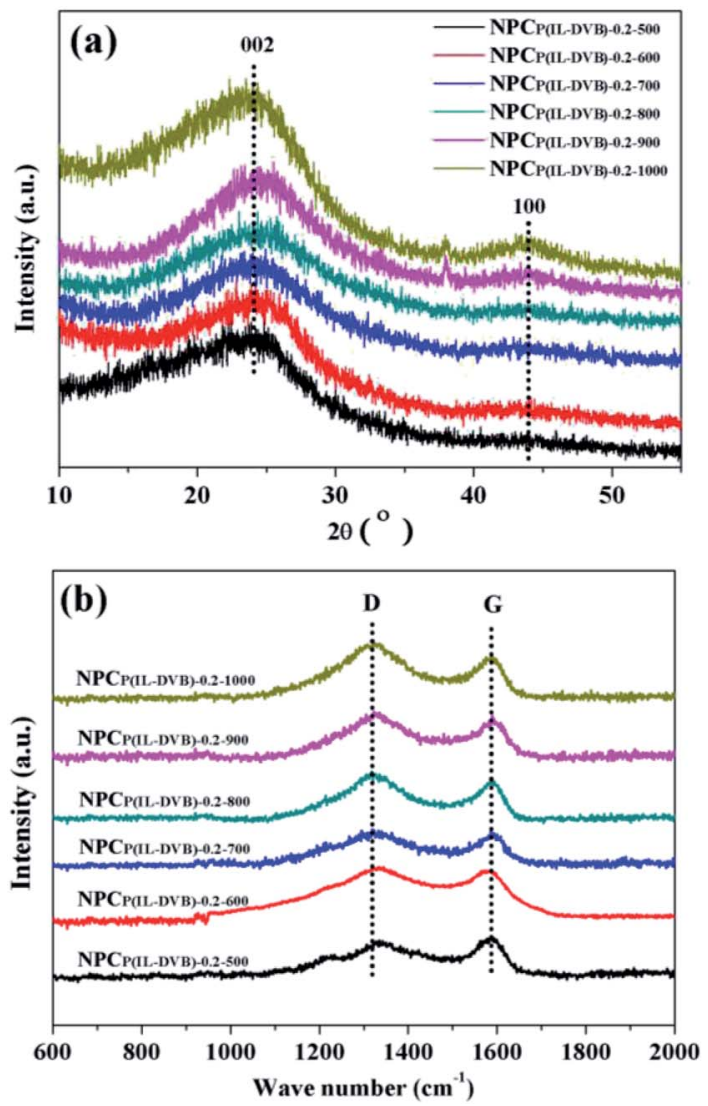

Fig. 6 (a) XRD-spectra and (b) Raman-spectra of NPCs from different carbonization temperature. to $1000{ }^{\circ} \mathrm{C}$, the surface microstructure has not obviously changed. The results indicated that the porosity of NPCs was influenced by carbonization temperature, which was consistent with the results obtained by nitrogen adsorption-desorption experiments.

The images of TEM and HR-TEM of $\mathrm{NPC}_{\mathrm{P}(\mathrm{IL}-\mathrm{DVB})-0.2-800}$ were showed in Fig. 5. From TEM image, abundant pores with the size of $2-4 \mathrm{~nm}$ were observed (Fig. 5a). The HR-TEM image of $\mathrm{NPC}_{\mathrm{P}(\mathrm{IL}-\mathrm{DVB})-0.2-800}$ found that the most graphitic layers in NPC were bent and disordered, and only in two small areas found orderly graphitic layers (in yellow circle) (Fig. $5 \mathrm{~b}$ ). These results were similar with nitrogen doped carbon materials by J. P. Paraknowitsch using ionic liquids [EMIM][dca] and [MBP][dca] as precursors. ${ }^{38,40}$

XRD and Raman spectra were employed to further investigate the crystallite structure of NPCs. Fig. 6a showed all NPC samples from different carbonization temperature possess broad stacking peaks at $24.2^{\circ}$ and $43.4^{\circ}$, which related to graphite (002) and (100) plane, demonstrated the amorphous characteristics of all NPC samples. ${ }^{31}$ The degree of graphitization of NPCs can be easily followed by Raman-spectroscopy. All samples revealed two characteristic peaks at about 1318 and $1588 \mathrm{~cm}^{-1}$, which were attributed to typical D- and G-band (see Fig. 6b). The level of disordered structure was related to D-band, whereas G-band was reveal the degree of graphitization. ${ }^{49,50}$ The intensity of the D-bands was higher than that of the G-bands in
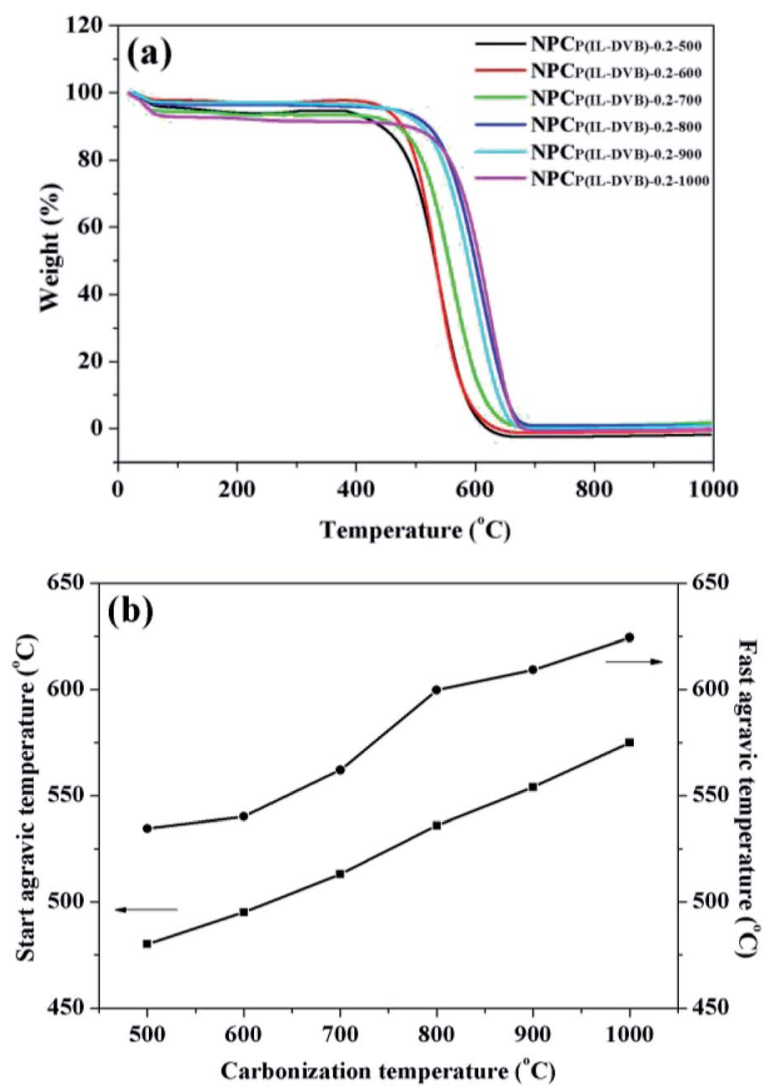

Fig. 7 (a) TG curves and (b) loss start and fastest agravic temperature under air of NPCs from different carbonization temperature. 

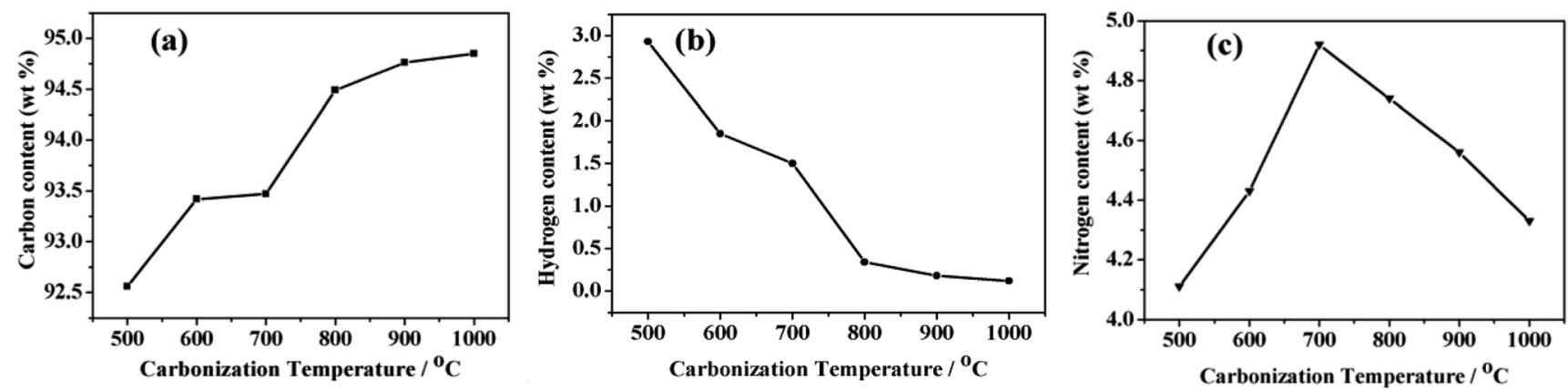

Fig. 8 (a) $\mathrm{C}$, (b) $\mathrm{H}$ and (c) N content of NPCs from different carbonization temperature.

all NPC samples (concrete dates see Fig. S4 in ESI $\dagger$ ). These results indicated that the disordered structure was dominant in NPCs. The similar results were also reported by J. P. Paraknowitsch on the polycondensation of ionic liquid [EMIM][dca] towards nitrogen doped carbon materials..$^{38,40}$

The oxidation resistance and heat resistance were important merits of NPCs. ${ }^{1-3}$ The oxidation resistance of NPCs from different carbonization temperature was investigated by TGA

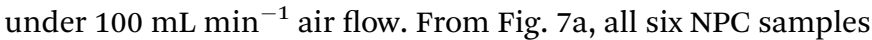
had a $3-7 \%$ weight loss from room temperature to $100{ }^{\circ} \mathrm{C}$, which came from NPCs surface absorbed water. From 100 to $400{ }^{\circ} \mathrm{C}$, there were not evident weight changes of all NPCs, showed preferable stability. All six NPC samples loss weight rapidly about 450 to $600{ }^{\circ} \mathrm{C}$ because of the burning, and the weight was decline to "zero" about $700{ }^{\circ} \mathrm{C}$. In order to investigate the differences in detail, the weight loss start temperature and the loss fastest temperature through tangent line method with software of Universal Analysis 2000 were listed in Fig. $7 \mathrm{~b}$. The loss start temperature of $\mathrm{NPC}_{\mathrm{P}(\mathrm{IL}-\mathrm{DVB})-0.2-500}$ was $480^{\circ} \mathrm{C}$, and the loss fastest temperature was $534^{\circ} \mathrm{C}$. With the carbonization temperature increasing, the start temperature and loss fastest temperature increased and reached to 575 and $624{ }^{\circ} \mathrm{C}$ at the carbonization temperature of $1000{ }^{\circ} \mathrm{C}$. These results indicated that the oxidation resistance and heat resistance were improved with the increase of carbonization temperature.

The elemental components of NPCs were obtained by chemical analysis (Fig. 8). With the increase of carbonization temperature from 500 to $1000{ }^{\circ} \mathrm{C}$, the carbon content was increasing and hydrogen content was decreasing. Meanwhile, nitrogen content was firstly increasing and then decreasing slowly. The unceasingly degradation of alkyl groups from incomplete carbonization NPCs (see IR spectra in Fig. 3a) at temperature of $500-700{ }^{\circ} \mathrm{C}$, led to dropping of $\mathrm{H}$ content, whereas increasing of $\mathrm{C}$ and $\mathrm{N}$ contents. Above $700{ }^{\circ} \mathrm{C}$, it was possibly the continuation of carbonization and the slight decomposition of $\mathrm{N}$ doped heterocyclic ring in graphitic layers, resulted in the increasing of $\mathrm{C}$ content and the decreasing of $\mathrm{H}$ and $\mathrm{N}$ content. ${ }^{23,40,48,51}$

The bonding environment of nitrogen and carbon atoms can be probed by XPS spectra. ${ }^{21-23,40}$ High-resolution N1s spectra of $\mathrm{NPC}_{\mathrm{P}(\mathrm{IL}-\mathrm{DVB})-0.2-800}$ were fitted into three individual subpeaks located at 398.43, 400.68 and $404.16 \mathrm{eV}$, in accordance with pyridinic-(N-6), pyrrolic- $(\mathrm{N}-5)$ and oxidized- $\mathrm{N}(\mathrm{N}-X)$, respectively (see Fig. 9a). According to the intensity of the subpeaks, the amount of different nitrogen bonding state was N-5 $>\mathrm{N}-6>\mathrm{N}-X$. The bonding structures of the nitrogen revealed in the N1s-XPS spectra were further supported by respective results of the C1s spectra (see Fig. 9b), which exhibiting graphite-like carbon $(284.78 \mathrm{eV})$, the nitrogen binding carbon $(\mathrm{C}-\mathrm{N}, 286.07 \mathrm{eV})$, and a weakly peak at $290.42 \mathrm{eV}$ may be oxidized form carbon (C$X){ }^{40,52}$ All N1s and C1s spectra of NPCs from different carbonization temperature were showed in Fig. S5 and S6 (see the ESI $\dagger$ ).

\section{Electrochemical properties of NPCs}

The electrochemical properties of NPCs were evaluated through cyclic voltammetry (CV), galvanostatic charge-discharge (GCD) and electrochemical impedance spectroscopy (EIS). CV was usually employed to evaluate the potential possibility of
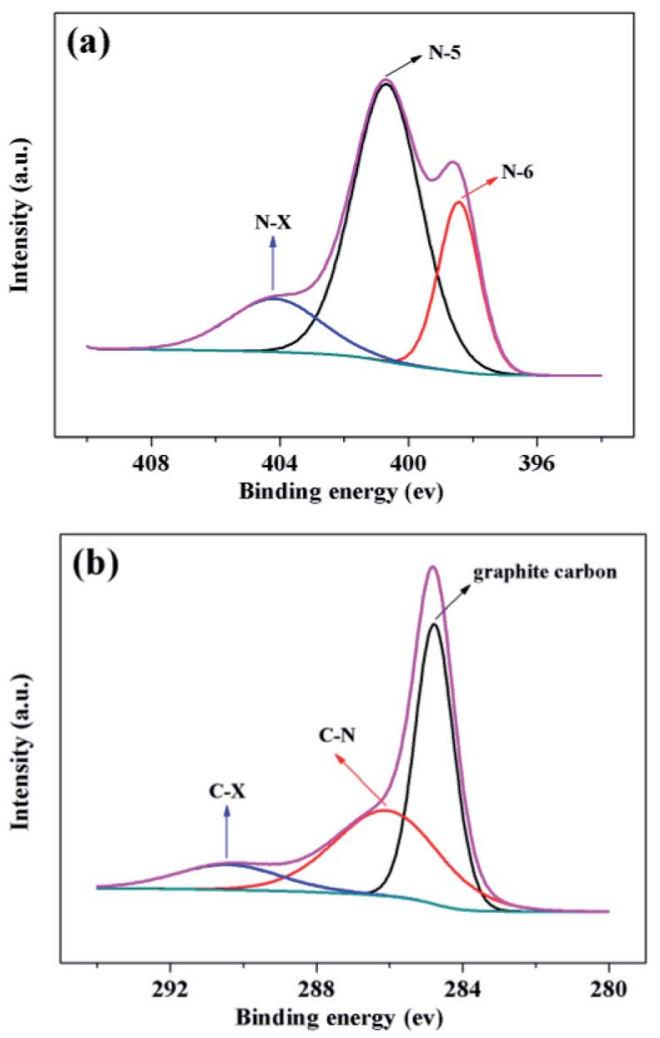

Fig. 9 (a) N1s spectra and (b) C1s spectra of NPC $C_{P(I L-D V B)-0.2-800}$ by XPS. 
materials used for supercapacitor. The CV curves of NPCs at scan rate of $20 \mathrm{mV} \mathrm{s}^{-1}$ were listed in Fig. 10a. The curves of $\mathrm{NPC}_{\mathrm{P}(\mathrm{IL}-\mathrm{DVB})-0.20-500}, \mathrm{NPC}_{\mathrm{P}(\mathrm{IL}-\mathrm{DVB})-0.20-600}$ and $\mathrm{NPC}_{\mathrm{P}(\mathrm{IL}-\mathrm{DVB})-0.20-700}$ presented "rugby-like" shape and the accordingly enclosed area were narrow. Meanwhile, the CV curves of NPCs carbonization above $800{ }^{\circ} \mathrm{C}$ were "box-like" shape and lenient, especially, $\mathrm{NPC}_{\mathrm{P}(\mathrm{IL}-\mathrm{DVB})-0.20-900}$ performed larger enclosed area, which meant having a certain potential as electrode materials for supercapacitor. The GCD curves of NPCs at $1.0 \mathrm{~A} \mathrm{~g}^{-1}$ current density were showed in Fig. 10b. All curves presented "isosceles triangle-like" shape, and had no obvious "drop" at discharge process. Particularly, $\mathrm{NPC}_{\mathrm{P}(\mathrm{IL}-\mathrm{DVB})-0.2-900}$ performed longer charge-discharge time, meant higher specific capacitance.
Fig. 10c showed the specific capacitance of NPCs at different current density. As the carbonization temperature increased, the specific capacitance of NPCs was improving and the rate capability was also promoting. Especially, $\mathrm{NPC}_{\mathrm{P}(\mathrm{IL}-\mathrm{DVB})-0.2-900}$ displayed better electrochemical property. The specific capacitances were up to $243 \mathrm{~F} \mathrm{~g}^{-1}$ at $0.1 \mathrm{~A} \mathrm{~g}^{-1}$, and $192 \mathrm{~F} \mathrm{~g}^{-1}$ at $2.0 \mathrm{~A} \mathrm{~g}^{-1}$, revealing a better rate capability. As comparison, a commercialized activated carbon FLS with BET surface area of $1845 \mathrm{~m}^{2} \mathrm{~g}^{-1}$ and total pore volume of $0.99 \mathrm{~cm}^{3} \mathrm{~g}^{-1}$ was used as a reference. The GCD curves at current density of $0.5 \mathrm{~A} \mathrm{~g}^{-1}$ (potential range of -1.1 to $-0.1 \mathrm{~V}$ ) were shown in Fig. 10d. Either $\mathrm{NPC}_{\mathrm{P}(\mathrm{IL}-\mathrm{DVB})-0.2-900}$ or FLS presented a linear GCD curve without obvious ohmic drop, indicating that both of them
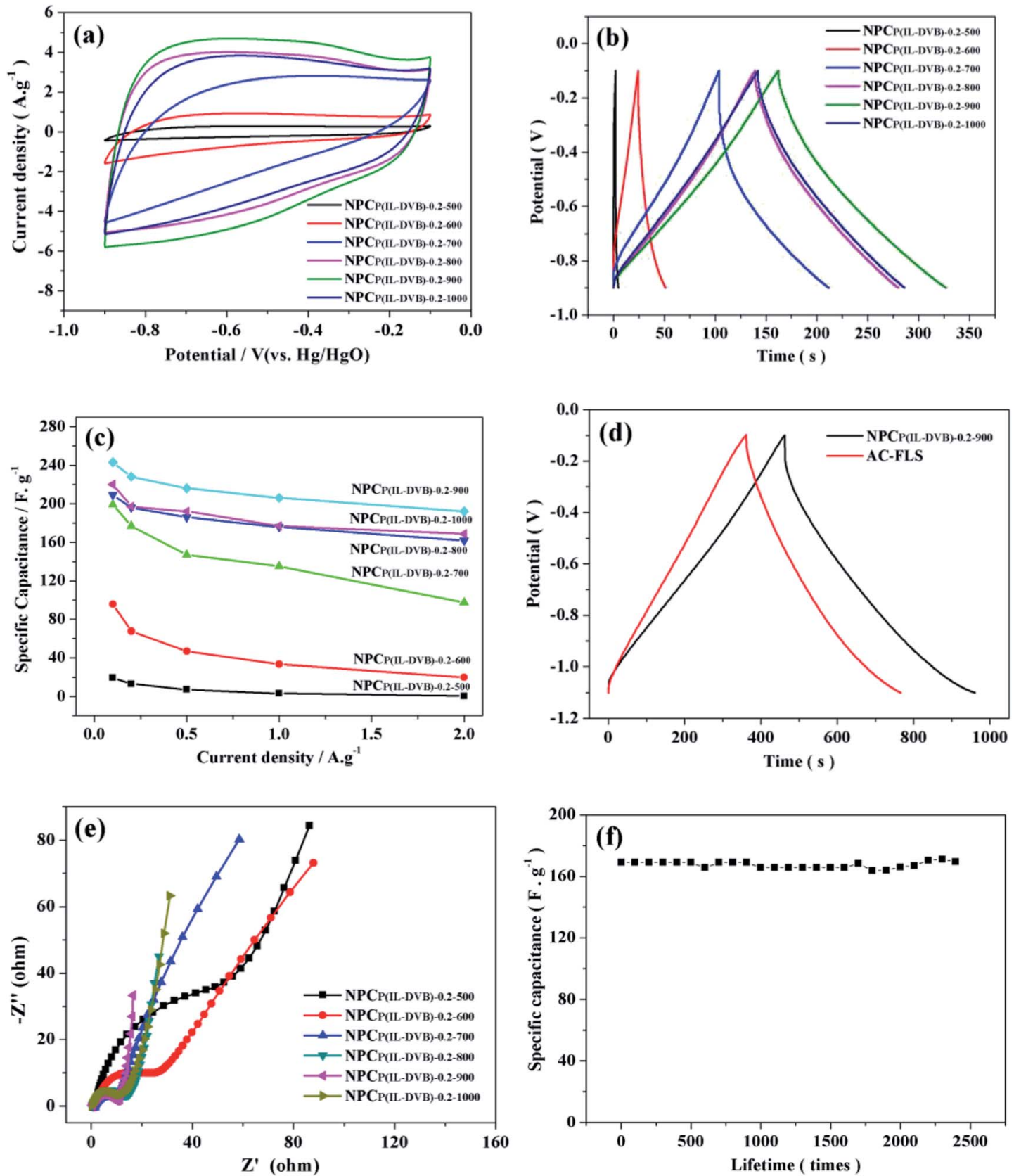

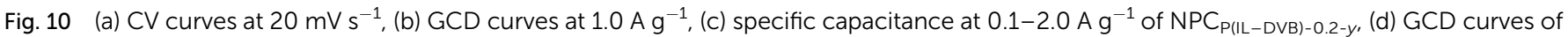
$N_{P C} C_{P(I L-D V B)-0.2-900}$ and AC-FLS at $0.5 \mathrm{~A} \mathrm{~g}^{-1}$, (e) EIS cures of NPC $C_{P(I L-D V B)-0.2-y}$ and (f) GCD life at $2.0 \mathrm{~A} \mathrm{~g}^{-1}$ of NPC $_{P(I L-D V B)-0.2-1000}$. 
possess a good capacitive behavior under this current density. However, the specific capacitance of $\mathrm{NPC}_{\mathrm{P}(\mathrm{IL}-\mathrm{DVB})-0.2-900}$ reached $248 \mathrm{~F} \mathrm{~g}^{-1}$ (calculated from the gravimetric discharge process according to $C=I \Delta t / \Delta V)$ in this condition, larger than that of the FLS $\left(202 \mathrm{~F} \mathrm{~g}^{-1}\right)$. The EIS curves were also measured, Fig. 10e showed the Nyquist plots collected in the frequency range of 0.01-10 kHz. It was found that the slope curves of six samples in low frequency region were enhancing with NPCs the increase of carbonization temperature. $\mathrm{NPC}_{\mathrm{P}(\mathrm{IL}-\mathrm{DVB})-0.2-900}$ was near to $90^{\circ}$, indicating lower resistance in charge transfer and ion diffusion processes of supercapacitors. It was also found that the semicircular diameters of the high-frequency portions of the six impedance curves decreased with the carbonization temperature increasing, indicating the $R_{\mathrm{s}}$ decreasing and electrical conductivity increasing. ${ }^{25-28} \mathrm{NPC}_{\mathrm{P}(\mathrm{IL}-\mathrm{DVB})-0.2-900}$ performed good electrochemical property that may be caused by the higher specific surface area, suitable pore size distribution ${ }^{53-55}$ and suitable $\mathrm{N}$ content. ${ }^{20-26}$

In order to satisfy commercial application, especially in electric vehicle industry, quick charge-discharge and long cycle life demand of supercapacitor is impending. ${ }^{21}$ It was important to investigate the specific capacitance under high current density and retention rate at long cycle charge-discharge. The cycle life of charge-discharge at $2 \mathrm{~A} \mathrm{~g}^{-1}$ was also tested (see Fig. 10f), the specific capacitance of $\mathrm{NPC}_{\mathrm{P}(\mathrm{IL}-\mathrm{DVB})-0.2-1000}$ maintained around $169 \mathrm{~F} \mathrm{~g}^{-1}$ (the retention rate was nearly $100 \%$ ) with no recession through 2400 times recycle. Such characteristic proved that pseudocapacitance effect introduced by nitrogen was stable with cycling, although the nitrogen content was lower than NPC from other ionic liquids. ${ }^{38-43}$ We speculate NPCs of this report will have excellent performance in acidic electrolytes. ${ }^{20}$ There will be good application prospect of NPCs in supercapacitor electrode materials.

\section{Conclusions}

A kind of nitrogen-doped porous carbon materials with 4-5\% nitrogen content and abundant pores, have successfully been prepared by carbonization of cross-linked poly(ionic liquid) with $\mathrm{SiO}_{2}$ template under nitrogen atmosphere above $600{ }^{\circ} \mathrm{C}$. The BET specific surface area of corresponding NPCs under the optimized condition can be up to $1324 \mathrm{~m}^{2} \mathrm{~g}^{-1}$, and total pore volume was $1.41 \mathrm{~cm}^{3} \mathrm{~g}^{-1}$. The graphitic layers in NPCs were amorphous and disordered, and the nitrogen bonding states were mainly pyrrolic- and pyridinic-N. The NPCs presented high specific capacitance (up to $243 \mathrm{~F} \mathrm{~g}^{-1}$ ), and excellent rate capability as the electrode material for supercapacitor, in galvanostatic charge-discharge process over a wide current density range in $6 \mathrm{M} \mathrm{KOH}$ electrolyte. The retention rate of specific capacitance was nearly $100 \%$ at $2 \mathrm{~A} \mathrm{~g}^{-1}$ through 2400 times recycle. We expect that NPCs of this report will have excellent performance in acidic electrolyte and a good application prospect in supercapacitor electrode materials.

\section{Conflicts of interest}

There are no conflicts to declare.

\section{Acknowledgements}

We thank the National Key Research and Development Program of China (2017YFA0403102), the National Natural Science Foundation of China (21573072, 21773068, 21811530273), and Shanghai Leading Academic Discipline Project (B409) for financial support.

\section{References}

1 Y. Zhai, Y. Dou, D. Zhao, P. Fulvio, R. T. Mayes and S. Dai, Adv. Mater., 2011, 23, 4828-4850.

2 M. Li, F. Xu, H. Li and Y. Wang, Catal. Sci. Technol., 2016, 6, 3670-3693.

3 M. Inagaki, M. Toyoda, Y. Soneda and T. Morishita, Carbon, 2018, 132, 104-140.

4 C. Pan, L. Qiu, Y. Peng and F. Yan, J. Mater. Chem., 2012, 22, 13578-13584.

5 T.-P. Fellinger, F. Hasché, P. Strasser and M. Antonietti, J. Am. Chem. Soc., 2012, 134, 4072-4075.

6 Y. Liu, Y. Zhang, C. Zhai, X. Li and L. Mao, Mater. Lett., 2016, 166, 16-18.

7 J. Gao, N. Ma, Y. Zheng, J. Zhang, J. Gui, C. Guo, H. An, X. Tan, Z. Yin and D. Ma, ChemCatChem, 2017, 9, 1601-1609.

8 X. Zhou, Y. Gao, S. Deng, S. Cheng, S. Zhang, H. Hu, G. Zhuang, X. Zhong and J. Wang, Ind. Eng. Chem. Res., 2017, 56, 11100-11110.

9 J. Gao, C. He, J. Liu, P. Ren, H. Lu, J. Feng, Z. Zou, Z. Yin, X. Wen and X. Tan, Catal. Sci. Technol., 2018, 8, 1142-1150.

10 N. Zdolsěk, A. Dimitrijević, M. Bendová, J. Krstić, R. P. Rocha, J. L. Figueiredo, D. Bajuk-Bogdanović, T. TrtićPetrović and B. Šljukić, ChemElectroChem, 2018, 5, 10371046.

11 P. F. Fulvio, J. S. Lee, R. T. Mayes, X. Wang, S. M. Mahurin and S. Dai, Phys. Chem. Chem. Phys., 2011, 13, 13486-13491.

12 L. Zhang, K. Cai, F. Zhang and Q. Yue, Chem. Res. Chin. Univ., 2015, 31, 130-137.

13 J. Gong, H. Lin, M. Antonietti and J. Yuan, J. Mater. Chem. A, 2016, 4, 7313-7321.

14 J. Gong, M. Antonietti and J. Yuan, Angew. Chem., Int. Ed., 2017, 56, 7557-7563.

15 M. Sarker, H. J. An, D. K. Yoo and S. H. Jhung, Chem. Eng. J., 2018, 338, 107-116.

16 L. Zhao, Y. S. Hu, H. Li, Z. Wang and L. Chen, Adv. Mater., 2011, 23, 1385-1388.

17 J. Balach, H. Wu, F. Polzer, H. Kirmse, Q. Zhao, Z. Wei and J. Yuan, RSC Adv., 2013, 3, 7979-7986.

18 Y. Shao, J. Sui, G. Yin and Y. Gao, Appl. Catal., B, 2008, 79, 89-99.

19 F. Hasche, T.-P. Fellinger, M. Oezaslan, J. P. Paraknowitsch, M. Antonietti and P. Strasser, ChemCatChem, 2012, 4, 479483.

20 G. Lota, B. Grzyb, H. Machnikowska, J. Machnikowski and E. Frackowiak, Chem. Phys. Lett., 2005, 404, 53-58.

21 W. Li, D. Chen, Z. Li, Y. Shi, Y. Wan, J. Huang, J. Yang, D. Zhao and Z. Jiang, Electrochem. Commun., 2007, 9, 569573. 
22 L. Sun, H. Zhou, L. Li, Y. Yao, H. Qu, C. Zhang, S. Liu and Y. Zhou, ACS Appl. Mater. Interfaces, 2017, 9, 26088-26095.

23 W. Tian, H. Zhang, H. Sun, M. O. Tade and S. Wang, Carbon, 2017, 118, 98-105.

24 F. Zeng, Z. Li, X. Li, J. Wang, Z. Kong, Y. Sun, Z. Liu and H. Feng, Appl. Surf. Sci., 2019, 467, 229-235.

25 D. Tang, Y. Luo, W. Lei, Q. Xiang, W. Ren, W. Song, K. Chen and J. Sun, Appl. Surf. Sci., 2018, 462, 862-871.

26 L. Shi, L. Jin, Z. Meng, Y. Sun, C. Li and Y. Shen, RSC Adv., 2018, 8, 39937-39947.

27 K. Krukiewicz, M. Krzywiecki, M. J. P. Biggs and D. Janas, RSC Adv. , 2018, 8, 30600-30609.

28 Y. LV, Y. Zhou, Z. Shao, J. Wei, L. Li and Y. Wang, RSC Adv., 2018, 8, 28944-28952.

29 T. Liu, C. Jiang, W. You and J. Yu, J. Mater. Chem. A, 2017, 5, 8635-8643.

30 L. Winkless, Mater. Today, 2016, 19, 422.

31 V. Veeramani, M. Sivakumar, S. Chen, R. Madhu, H. R. Alamri, Z. A. Alothman, M. S. A. Hossain, C. Chen, Y. Yamauchi, N. Miyamoto and K. C.-W. Wu, RSC Adv., 2017, 7, 45668-45675.

32 Z. Chen, S. Ye, S. D. Evans, Y. Ge, Z. Zhu, Y. Tu and X. Yang, Small, 2018, 14, 1704015-1704023.

33 P. Wasserscheid and W. Keim, Angew. Chem., Int. Ed., 2000, 39, 3773-3789.

34 J. Lu, F. Yan and J. Texter, Prog. Polym. Sci., 2009, 34, 431448.

35 J. Yuan and M. Antonietti, Polymer, 2011, 52, 1469-1482.

36 T.-P. Fellinger, A. Thomas, J. Yuan and M. Antonietti, Adv. Mater., 2013, 25, 5838-5855.

37 J. S. Lee, X. Wang, H. Luo, G. A. Baker and S. Dai, J. Am. Chem. Soc., 2009, 131, 4596-4597.

38 J. P. Paraknowitsch, J. Zhang, D. S. Su, A. Thomas and M. Antonietti, Adv. Mater., 2010, 22, 87-92.
39 J. S. Lee, X. Wang, H. Luo and S. Dai, Adv. Mater., 2010, 22, 1004-1007.

40 J. P. Paraknowitsch, A. Thomas and M. Antonietti, J. Mater. Chem., 2010, 20, 6746-6758.

41 N. Fechler, T.-P. Fellinger and M. Antonietti, Adv. Mater., 2013, 25, 75-79.

42 X. Wang and S. Dai, Angew. Chem., Int. Ed., 2010, 49, 66646668.

43 Q. Zhao, T.-P. Fellinger, M. Antonietti and J. Yuan, J. Mater. Chem. A, 2013, 1, 5113-5120.

44 D. Kuzmicz, P. Coupillaud, Y. Men, J. Vignolle, G. Vendraminetto, M. Ambrogi, D. Taton and J. Yuan, Polymer, 2014, 55, 3423-3430.

45 H. Zhou, J. Song, X. Kang, J. Hu, Y. Yang, H. Fan, Q. Meng and B. Han, RSC Adv., 2015, 5, 15267-15273.

46 Y. Zhang, B. Wang, E. H. M. Elageed, L. Qin, B. Ni, X. Liu and G. Gao, ACS Macro Lett., 2016, 5, 435-438.

47 S. E. Zakiyan, M. H. N. Famili and M. Ako, J. Mater. Sci., 2014, 49, 6225-6239.

48 J. P. Paraknowitsch and A. Thomas, Macromol. Chem. Phys., 2012, 213, 1132-1145.

49 A. C. Ferrari and J. Robertson, Phys. Rev. B: Condens. Matter Mater. Phys., 2000, 61, 14095-14107.

50 S. Reich and C. Thomsen, Philos. Trans. R. Soc., A, 2004, 362, 2271-2288.

51 M. Kodamaa, J. Yamashita, Y. Soneda, H. Hatori, S. Nishimura and K. Kamegawa, Mater. Sci. Eng., B, 2004, 108, 156-161.

52 C. Silien, M. Buck, G. Goretzki, D. Lahaye, N. R. Champness, T. Weidner and M. Zharnikov, Langmuir, 2009, 25, 959-967.

53 S. Yoon, J. W. Lee, T. Hyeon and S. M. Oh, J. Electrochem. Soc., 2000, 147, 2507-2512.

54 E. Frackowiak and F. Beguin, Carbon, 2001, 39, 937-950.

55 A. G. Pandolfo and A. F. Hollenkamp, J. Power Sources, 2006, 157, 11-27. 